\section{Porque os Nossos "Arquivos” São Fundamentais para o Futuro da Endocrinologia Nacional}

A PÓs O SUCESSO DO $23^{\circ}$. CBEM, em Recife, com mais de 3000 participantes e com inúmeras apresentações de trabalhos desenvolvidos por todo o País de qualidade internacional, algumas reflexões quanto ao futuro de nossa Sociedade, em termos científicos, me parecem necessárias.

Infelizmente, já estou no grupo dos mais velhos participantes da SBEM. Contudo, os mais de 30 anos de participação efetiva nos vários congressos e simpósios, me permitem ter uma visão muito boa da nossa evolução científica. Certamente, em alguns centros, estamos hoje em nível de produção comparável aos melhores do mundo. Muito deste sucesso se deve aos esforços dos Programas de Pós-Graduação espalhados pelo País. O MEC, através da CAPES, avalia anualmente todos os Programas de Mestrado e Doutorado e a cada 3 anos emite um conceito, que varia de 1 a 7. Na área médica só existe um Programa com conceito 7. Contudo, na nossa área específica, temos alguns poucos 6 e vários 5 .

Um dos critérios mais relevantes nesta avaliação é a produção científica. Sua valorização é função do índice de impacto (ISI) do periódico, medido em função do número de citações dos artigos daquela revista. Portanto, uma das políticas que deveríamos adotar para melhorar a classificação dos ABE\&M seria a de citarmos os seus artigos nos trabalhos submetidos. Não há qualquer dúvida quanto ao padrão de qualidade dos artigos publicados nos ABE\&M. Nos últimos anos, fruto de um trabalho continuado dos Editores-Chefe e dos Editores Associados na seleção dos revisores, na qualidade de impressão, na manutenção da periodicidade da publicação, e principalmente na melhora da qualidade dos trabalhos submetidos.

Hoje não há a desculpa de não encontrar os artigos para citá-los, uma vez que estão todos na íntegra no site do SciELO (mais um grande avanço na divulgação da produção científica Nacional). Possivelmente, em futuro próximo, teremos os textos vertidos para o Inglês na versão online, o que dará uma maior visibilidade aos trabalhos. Caso consigamos atingir um índice de impacto maior, nossa revista será mais valorizada. Isto acarretará maior procura para submissão de artigos, com conseqüente melhora na qualidade. Para quem ainda não sabe, os $\mathrm{ABE} \& \mathrm{M}$ são indexados no PUBMED, o que confere uma classificação de revista internacional $\mathrm{C}$ no comitê de Medicina I da CAPES, no qual somos avaliados. Se conseguirmos a indexação no Journal Citation Report (JCR), que atribui o ISI, passaremos automaticamente para internacional $\mathrm{B}$ e se atingirmos índice de impacto maior que 1, para internacional A, o que possibilitaria acentuada melhora na avaliação dos Programas.

Além destes argumentos, todos que militamos na pesquisa sabemos o quão está difícil conseguir publicar em revistas internacionais de primeira linha. Não quero entrar nas causas, pois acredito que sofremos ainda alguma discriminação por sermos de país em desenvolvimento. A possibilidade de termos uma revista de padrão internacional sob nossa responsabilidade aumenta muito a visibilidade de nossos trabalhos. Isto é fundamental, particularmente para os jovens pesquisadores que buscam seu espaço. As agên-

\section{carta ao editor}

Mário Vaisman
Professor Titular de Medicina, Disciplina de Endocrinologia, Departamento de Clinica Médica, Faculdade de Medicina da Universidade Federal do Rio de Janeiro - UFRJ 
cias de fomento também julgam os pedidos de bolsas e auxílios em função da produção científica e outros critérios específicos para cada Edital. Como a competitividade aumenta a cada ano, mais uma vez em função da qualidade dos egressos dos Programas de Pós-Graduação, quanto mais publicações em periódicos de maior impacto melhor a pontuação.

Portanto, conclamo a todos os orientadores e pesquisadores a prestigiarem nossos ABE\&M submetendo seus artigos para publicação e, particularmente, citando-o com mais freqüência. Certamente possuímos competência para termos uma revista Qualis A internacional, o que propiciará um grande salto da nossa Endocrinologia no cenário internacional.

Tenho certeza que a Diretoria da SBEM Nacional, sabedora da importância dos ABE\&M para a divulgação dos avanços da Endocrinologia Brasileira, não deixará de prover os recursos e meios para que o Corpo Editorial possa desenvolver adequadamente seu trabalho, que em última análise objetiva dar maior visibilidade internacional à nossa produção científica.

\section{Endereço para correspondência:}

Mário Vaisman

Disciplina de Endocrinologia, Departamento de Clínica

Médica

Faculdade de Medicina da Universidade Federal do Rio de Janeiro

Av. Brigadeiro Trompowski, s/n - llha do Fundão

21941-590 Rio de Janeiro, RJ

vaisman@hucff.ufr.br 